\title{
Influence of nucleating agent on the crystallization kinetics and morphology of polypropylene
}

\author{
Adriane Gomes Simanke ${ }^{1 *}$, Ana Paula de Azeredo ${ }^{1}$, Cristóvão de Lemos ${ }^{1}$ and Raquel Santos Mauler ${ }^{2}$ \\ ${ }^{1}$ Braskem S.A., Triunfo, $R S$, Brazil \\ ${ }^{2}$ Instituto de Química, Universidade Federal do Rio Grande do Sul - UFRGS, Porto Alegre, RS, Brazil \\ *adriane.simanke@braskem.com
}

\begin{abstract}
The influence of three nucleating agents from different generations on the crystallization behavior of propylene homopolymer was studied by differential scanning calorimetry (DSC) and atomic force microscopy (AFM). The amount of nucleating agent used varied between 1000 and 2200 ppm. The new generation nucleating agent, Hyperform ${ }^{\circledR}$ HPN-68L, accelerates the crystallization more efficiently than the other nucleating agents tested. It was also possible to verify the effects of agglomeration and negative interaction between calcium stearate and sodium benzoate. Furthermore, AFM images allowed to differentiate the crystals generated by Millad ${ }^{\circledR} 3988$ through the observation of a fibrillar intertwining network structure, with characteristic spacing and length of crystals, justifying its excellent performance to improve polypropylene optical properties.
\end{abstract}

Keywords: AFM, crystallization kinetics, morphology, nucleating agent, polypropylene.

\section{Introduction}

Propylene resins are one of the most versatile families of thermoplastics. Their semicrystalline nature and their structural stereoregularity allow controlling their physical and mechanical properties through a variety of variables such as molecular structure, molecular weight and molecular weight distribution, comonomer content and distribution, degree of crystallinity and morphology. Advances in the catalytic system, polymerization process and post reactor changes, including the use of different additives, allow to overcome polypropylene previous limitations, making it competitive with other polymers and materials. Polypropylene and its copolymers are widely used in applications ranging from durable parts such as exterior and interior parts of automobiles to disposable packaging such as bags. Although polypropylene faces some restrictions in applications that require outstanding optical properties, these can be improved by propene copolymerization with comonomers such as ethylene and butene or by the use of additives, as the nucleating agents. These foreign particles (as silica, talc and organic salts) added to polypropylene act as seeds of nucleation process, accelerating the crystallization rate ${ }^{[1]}$. Nucleating agents are being widely used in order to improve mechanical and optical properties of polypropylene and its copolymers. They are also used to accelerate polypropylene crystallization kinetics, reducing injection molding cycle times and, by consequence, reducing production costs. The nucleating agent efficiency depends on its particle size, morphology, chemical structure and behavior when incorporated into the polymer ${ }^{[2]}$. In order to maximize the nucleation efficiency and reach the best cost benefit ratio, nucleating agents evolved and there are various types in the market, from different chemical families. Although a large number of papers have been published regarding the use of nucleating agents in polypropylene, just a few ${ }^{[3-5]}$ describe in detail the influence of different nucleating agent structures on polypropylene morphology and crystallization kinetics. In this work, three commercial nucleating agents from different generations were evaluated and their influence on the crystallization kinetics and morphology were studied through atomic force microscopy (AFM) and differential scanning calorimetry (DSC).

\section{Materials and Methods}

\subsection{Materials}

A propylene homopolymer (PP) produced by Braskem (see characteristics in Table 1) was used to evaluate the performance of three commercial nucleating agents: 1,3:2,4-bis(3,4-dimethylbenzylidene)sorbitol (Millad ${ }^{\circledR} 3988$ from Milliken), identified as NA, sodium benzoate, identified as NB, and sodium bicycle[2,2,1] heptane dicarboxylate salt (Hyperform ${ }^{\circledR}$ HPN-68L from Milliken), identified as NC. At least three different concentrations of these nucleating agents were used: 1000, 1600 and 2200 ppm (Table 2).

\subsection{Sample preparation}

Polypropylene powder and nucleating agents were mixed in an intensive mixer, Mixaco CM-600D, at $1600 \mathrm{rpm}$, under nitrogen for $30 \mathrm{~s}$. It was also added $1200 \mathrm{ppm}$ of Irganox B-215 and $500 \mathrm{ppm}$ of calcium stearate (CaSt). Then, samples were extruded in a single screw extruder, Rulli EF-70, L/D $1: 25$, with $70 \mathrm{~mm}$ screw diameter. Temperatures of the five zones of the extruder were $180,185,190,195,200^{\circ} \mathrm{C}$ and the extruder screw speed was adjusted to $130 \mathrm{rpm}$.

Samples were compressed molded at $175{ }^{\circ} \mathrm{C} / 30$ ton in a hydraulic press (G302 Wabash equipment) to obtain films of 35-45 $\mu \mathrm{m}$ thickness to be used in the DSC and AFM analyses. 
Table 1. Polypropylene characteristics.

\begin{tabular}{|c|c|c|c|c|c|}
\hline \multirow[t]{2}{*}{ Sample } & $\begin{array}{c}\text { MFI } \\
230^{\circ} \mathrm{C} / 2.16 \mathrm{~kg} \\
\end{array}$ & Density & Mn & Mw & \multirow[t]{2}{*}{$\mathbf{M w} / \mathbf{M r}$} \\
\hline & $(\mathrm{g} / 10 \mathrm{~min})$ & $\left(\mathrm{g} / \mathrm{cm}^{3}\right)$ & $(\mathrm{kg} / \mathrm{mol})$ & $(\mathrm{kg} / \mathrm{mol})$ & \\
\hline PP & 20 & 0.905 & 39200 & 163700 & 4.2 \\
\hline
\end{tabular}

Table 2. Samples composition.

\begin{tabular}{|c|c|}
\hline $\mathbf{P P}$ & neat PP \\
\hline PP NA 1 & PP + 1000 ppm Millad ${ }^{\circledR} 3988$ \\
\hline PP NA 2 & PP +1600 ppm Millad ${ }^{\circledast} 3988$ \\
\hline PP NA 3 & $\mathrm{PP}+2200$ ppm Millad ${ }^{\circledR} 3988$ \\
\hline PP NB 1 & $\mathrm{PP}+1000 \mathrm{ppm}$ sodium benzoate \\
\hline PP NB 2 & $\mathrm{PP}+1600 \mathrm{ppm}$ sodium benzoate \\
\hline PP NB 3 & PP + 2200 ppm sodium benzoate \\
\hline PP NC 1 & $\mathrm{PP}+1000$ ppm Hyperform ${ }^{\circledast} \mathrm{HPN}-68 \mathrm{~L}$ \\
\hline PP NC 2 & $\mathrm{PP}+1600$ ppm Hyperform ${ }^{\circledast} \mathrm{HPN}-68 \mathrm{~L}$ \\
\hline PP NC 3 & $\mathrm{PP}+2200$ ppm Hyperform ${ }^{\circledast} \mathrm{HPN}-68 \mathrm{~L}$ \\
\hline
\end{tabular}

\subsection{Characterization techniques}

\subsubsection{Differential Scanning Calorimetry (DSC)}

Thermal behavior was analyzed by differential scanning calorimetry using a TA Q1000 DSC under nitrogen and connected to an intracooler that allowed sub ambient temperature control. The instrument was calibrated with indium. Film samples $(6 \pm 1 \mathrm{mg})$ were melted at $200^{\circ} \mathrm{C}$, held at this temperature for 5 minutes to ensure complete melting, cooled from $200{ }^{\circ} \mathrm{C}$ to $-20^{\circ} \mathrm{C}$ and heated from $-20^{\circ} \mathrm{C}$ to $200{ }^{\circ} \mathrm{C}$. All heating/cooling rates used were $10{ }^{\circ} \mathrm{C} / \mathrm{min}$. The melting temperature $(\mathrm{Tm})$ and enthalpy of fusion $\left(\Delta \mathrm{H}_{\mathrm{f}}\right)$ were taken from the second heating curve. Crystallinity degree $(\mathrm{Xc})$ is given by $\Delta \mathrm{H}_{\mathrm{f}} / \mathrm{H}_{\mathrm{f}}^{0}$, where $\mathrm{H}_{\mathrm{f}}^{0}$ is the enthalpy of fusion of $100 \%$ crystalline PP $(190 \mathrm{~J} / \mathrm{g})$.

The isothermal crystallization experiments were carried out in a TA Q1000 DSC equipped with a liquid nitrogen cooling system. Samples were heated to $200^{\circ} \mathrm{C}$, held at this temperature for 5 minutes to ensure complete melting and quenched to the selected isothermal crystallization temperature at a nominal cooling rate of $140{ }^{\circ} \mathrm{C} / \mathrm{min}$. In order to calculate the Avrami coefficients, three different crystallization temperatures were used: $146.5^{\circ} \mathrm{C}, 147^{\circ} \mathrm{C}$ and $147.5^{\circ} \mathrm{C}$.

Analyses of the experimental time-dependent relative crystallinity function $\theta(t)$ were carried out according to the Avrami model ${ }^{[6-9]}$, which is given by:

$$
\theta(t)=1-\exp \left(-k t^{n}\right)
$$

where $\mathrm{k}$ is the Avrami rate constant, and $\mathrm{n}$ is the Avrami exponent. Both $\mathrm{k}$ and $\mathrm{n}$ are constants specific to a given crystalline morphology and type of nucleation for a particular crystallization condition ${ }^{[7]}$. Another parameter to evaluate the nucleating performance is the crystallization half time $\left(t_{12}\right)^{[8]}$, which is a measure of the time it takes from the onset of crystallization until the crystallization is half completed.

\subsubsection{Scanning Electron Microscopy (SEM)}

The morphology of the nucleating agent surface was investigated with scanning electron microscopy (Hitachi TM-1000 model). Samples were analyzed in the powder form without previous sputter-coated and the electron micrographs were taken using an acceleration voltage of $15.0 \mathrm{kV}$.

\subsubsection{Atomic Force Microscopy (AFM)}

AFM images were obtained using Veeco NanoScope $V$ atomic force microscopy and Veeco diTAC heater system operating under heating conditions. Topography and phase images were simultaneously collected in tapping mode at $512 \times 512$ lines standard resolution. Veeco single side coated silicon cantilevers were used with resonant frequency at $366-401 \mathrm{kHz}$. According to the manufacturer's specifications, the cantilevers have a spring constant of $20-80 \mathrm{~N} / \mathrm{m}$, length of $110-140 \mu \mathrm{m}$, width of $25-35 \mu \mathrm{m}$ and the radius of the tip is $2-5 \mathrm{~nm}$. Film samples of nominal thickness of $35-45 \mu \mathrm{m}$ and without previous surface treatment were subject to different scan areas using a scan rate between 0.0313 to $0.878 \mathrm{~Hz}$. Films were quickly heated to $200^{\circ} \mathrm{C}$ and kept at this temperature for $5 \mathrm{~min}$. In a second stage, the melted polymer was quickly cooled to the isotherm temperature of scanning to observe the crystallization step and lamellae growth. PP NA 1, PP NB 1 and PP NC 1 were analyzed at $155^{\circ} \mathrm{C}$ whereas neat $\mathrm{PP}$ was analyzed at $145^{\circ} \mathrm{C}$ and the isothermal crystallization time varied according to the crystallization rate.

\subsubsection{Optical properties - Haze and gloss $45^{\circ}$}

Haze measurements were carried out on a Haze Gard Plus made by BYK-Gardner, according to ASTM D 1003-00. Gloss measurements were carried out on a Micro Gloss $45^{\circ}$ made by BYK-Gardner, using light source $\mathrm{C}$, according to ASTM D 2457-03. Haze and gloss were measured using $1 \mathrm{~mm}$ x $60 \mathrm{~mm}$ x $60 \mathrm{~mm}$ injection molded plates. Injection molded plates were obtained using an Arburg Allrounder $270 \mathrm{U} 400-170$ equipment at $170 / 175 / 180 / 185 / 190^{\circ} \mathrm{C}$ barrel temperatures, $300 \mathrm{~cm}^{3} / \mathrm{s}$ injection flow, $60^{\circ} \mathrm{C}$ mold temperature (procedure according to ASTM D-3641). After injection molding, specimens were condicioned at $23 \pm 2{ }^{\circ} \mathrm{C}$ and $50 \pm 5 \% \mathrm{RH}$ for $40 \mathrm{~h}$.

\section{Results and Discussions}

\subsection{Nucleating agent morphology}

Scanning Electron Microscopy (SEM) analyses of the three nucleating agents used in this work were carried out in order to evaluate their morphology (Figure 1).

The nucleating agent NA shows fibrillar morphology whereas in NB and NC the predominant morphology is granular. Moreover, the granules of $\mathrm{NC}$ are smaller and more homogeneous than NB. It is also possible to observe the presence of some agglomerated particles in NB due to its hygroscopicity ${ }^{[10]}$.

\subsection{Thermal analysis characterization}

Comparing neat polypropylene (PP) with nucleated PP samples (Table 3 ), it is possible to observe that the addition of $1000 \mathrm{ppm}$ of nucleating agent is sufficient to cause a significant increase in the crystallization temperature (Tc). 


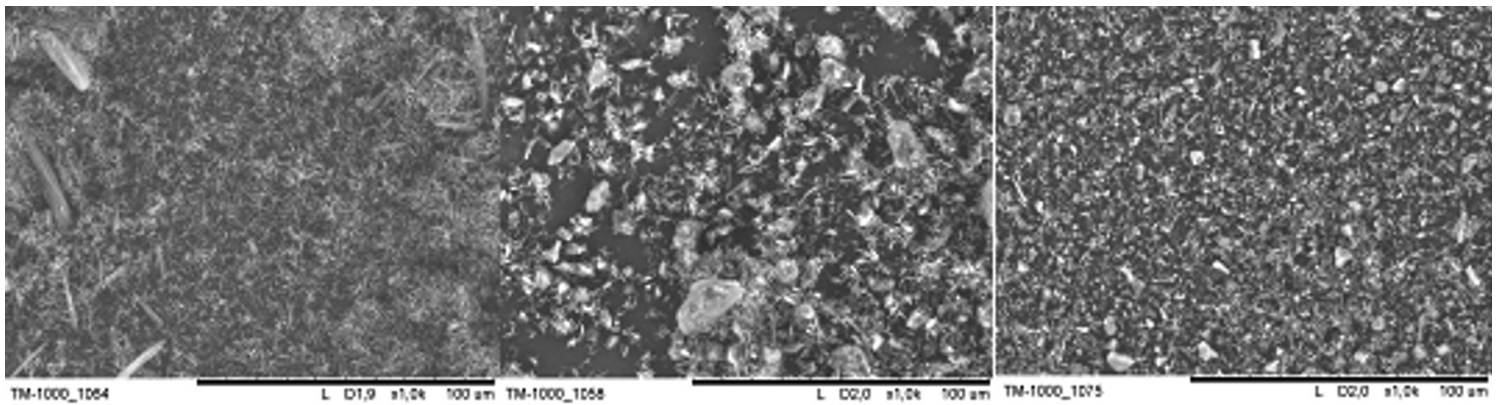

(a)

(b)

(c)

Figure 1. SEM images of nucleating agents (a) NA, (b) NB and (c) NC.

Among the three nucleating agents tested, the highest increase in Tc is obtained with NC. It is noted, however, that the increase of $\mathrm{Tc}$ is not proportional to the increment in the amount of nucleating agent. Crystallization temperatures of the samples with $1600 \mathrm{ppm}$ and $2200 \mathrm{ppm}$ of NA and NC are only $1{ }^{\circ} \mathrm{C}$ or $2{ }^{\circ} \mathrm{C}$ higher than the Tc of the samples with $1000 \mathrm{ppm}$, indicating that the lowest amount tested could be enough to improve the thermal properties. In the samples with NB, it is observed a decrease in Tc as the nucleating amount increases. This behavior indicates that the amount of NB used is above the ideal concentration to attain the highest nucleation rate and the excess of additive could be causing agglomeration, decreasing nuclei number and, by consequence, decreasing $\mathrm{Tc}^{[11]}$. Libster et al. ${ }^{[12]}$ showed that a good dispersion of NC in microemulsions causes super saturation since low amounts, indicating that higher amounts do not supply additional nuclei, that could explain the similar $\mathrm{Tc}$ values obtained for the different amounts of $\mathrm{NC}$ tested.

In order to verify if nucleating agent levels below $1000 \mathrm{ppm}$ also increase the crystallization temperature efficiently, samples with lower amounts of NC and NB were prepared and analyzed. Figure 2 shows the crystallization temperature as a function of the nucleating agent amount for PP samples nucleated with NC and NB.

Analyzing Figure 2, it is possible to see that there is an increase of Tc with increasing content of NC. Although the increase is small, it cannot be attributed to a poor dispersion, but to the fact that the maximum performance of $\mathrm{NC}$ is achieved at low concentrations ${ }^{[12]}$. In the case of $\mathrm{NB}$, it is possible to observe that the Tc increases as the nucleating agent amount increases from $200 \mathrm{ppm}$ to $1000 \mathrm{ppm}$, but above this concentration, it decreases. This behavior is in accordance with the agglomeration hypothesis that has been already discussed by Botkin et al. ${ }^{[13]}$.

\subsubsection{Isothermal crystallization kinetics}

The nucleated samples were isothermally crystallized at three different temperatures: $146.5^{\circ} \mathrm{C}, 147^{\circ} \mathrm{C}$ and $147.5^{\circ} \mathrm{C}$. Because neat PP did not crystallize at these temperatures, it was analyzed at $134{ }^{\circ} \mathrm{C}$ and $136^{\circ} \mathrm{C}$. The rate of evolution of the crystallization enthalpy with time was measured by DSC and the integration of $\mathrm{dHc} / \mathrm{dt}$ in the crystallization range is expressed as the relative crystallinity $(\mathrm{Xt})$ as a function of time.

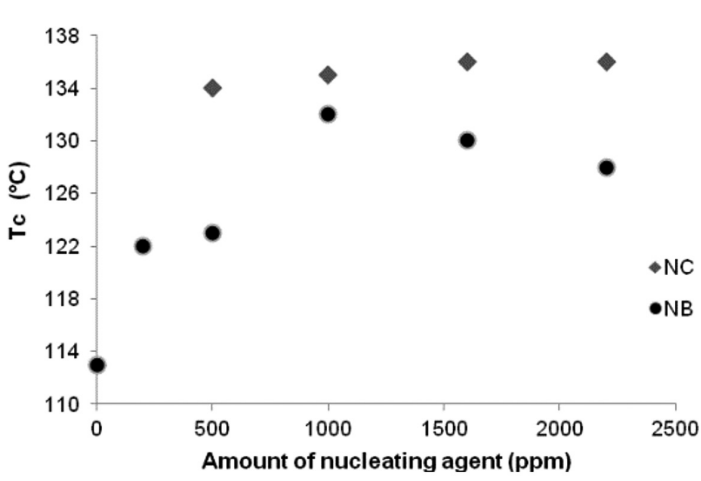

Figure 2. Crystallization Temperature as a Function of the Amount of Nucleating Agent.

Table 3. Thermal Properties of Neat PP and Nucleated PP Samples.

\begin{tabular}{cccc}
\hline Samples & $\mathbf{T c}\left({ }^{\circ} \mathbf{C}\right)$ & $\mathbf{T m}_{\mathbf{2}}\left({ }^{\circ} \mathbf{C}\right)$ & $\mathbf{X c}_{\mathbf{2}}(\mathbf{\%})$ \\
\hline PP & 113 & 162 & 58 \\
PP NA 1 & 130 & 165 & 56 \\
PP NA 2 & 132 & 165 & 58 \\
PP NA 3 & 132 & 165 & 60 \\
PP NB 1 & 132 & 165 & 59 \\
PP NB 2 & 130 & 165 & 57 \\
PP NB 3 & 128 & 164 & 55 \\
PP NC 1 & 135 & 165 & 59 \\
PP NC 2 & 136 & 165 & 58 \\
PP NC 3 & 136 & 165 & 60 \\
\hline
\end{tabular}

Since each nucleated sample showed similar behavior at the three different crystallization temperatures, only the crystallization kinetics curves obtained at $146.5^{\circ} \mathrm{C}$ for each nucleated sample will be presented.

Figure 3 shows the relative crystallinity curves as a function of time at $146.5^{\circ} \mathrm{C}$ for the three PP samples nucleated with NA. As the amount of NA is increased, it is observed a substantial increase in the crystallization rates, which is in accordance with some studies using sorbitol derivatives, such as NA, that indicate that they need a 
minimum concentration to begin having nucleating effects on polypropylene ${ }^{[14-16]}$.

Regarding PP samples nucleated with NB, it is possible to see that the crystallization rate decreases as the amount of NB agent is increased, which can be explained by the agglomeration of the additive that decreases the number of nuclei formed. Similar behavior is observed at all temperatures analyzed (Figure 4).

In the case of samples nucleated with $\mathrm{NC}$, the increase in the crystallization rate is not very significant as the amount of $\mathrm{NC}$ is increased, indicating that its maximum performance in terms of thermal properties is achieved with low concentrations (Figure 5).

Comparing the three nucleating agents, it is possible to conclude that the highest crystallization rate is obtained with $\mathrm{NC}$, in the three contents tested (1000 ppm, $1600 \mathrm{ppm}$ and $2200 \mathrm{ppm})$. NC accelerates the crystallization more efficiently than the other nucleating agents tested. The crystallization rates of samples nucleated with NB are intermediary to the ones achieved by the samples nucleated with NC and NA.

\subsubsection{Avrami parameters}

The Avrami coefficients of neat PP were calculated in only two temperatures and the $n$ values obtained (Table 4) were in agreement with values found in the literature ${ }^{[6,9]}$ for polypropylene. The Avrami coefficients of the nucleated samples were calculated at the three temperatures studied and the results are shown in Table 5. The $n$ values obtained for the nucleated samples are around 3.0, ranging between 2.1 and 3.4 , pointing to the formation of crystals varying between two-dimensional and three-dimensional structures. It was expected the decrease of $\mathrm{k}$ values with the increase of temperature, but some of the samples did not follow this tendency.

Regarding the crystallization half time $\left(\mathrm{t}_{1 / 2}\right)$, it is possible to observe the increase of $t_{1 / 2}$ values with the increase of $\mathrm{NB}$ content, confirming the agglomeration problem. It is observed a significant decrease in $t_{1 / 2}$ values as the amount of NA was increased from $1000 \mathrm{ppm}$ to $2200 \mathrm{ppm}$, while $t_{1 / 2}$ values are similar among the different levels of NC used.

Based on these values, one can conclude that $\mathrm{NC}$ accelerates the crystallization rate more effectively than the other nucleating agents studied.

\subsection{AFM characterization}

AFM characterization was carried out at different temperatures in order to define the better isothermal temperature to analyze the specimens. AFM height and phase images of PP obtained at 2 and 17 minutes at an isotherm of $145^{\circ} \mathrm{C}$ are showed in Figure 6.

In Figure 6a it is observed some dots indicating the presence of crystalline nuclei that characterizes the

Table 4. Avrami parameters for neat PP at different isothermal temperatures.

\begin{tabular}{cllllll}
\hline Parameters & \multicolumn{2}{c}{$\mathbf{n}$} & \multicolumn{2}{c}{$\mathbf{K}$} & \multicolumn{2}{c}{$\mathbf{t}_{1 / 2}(\mathbf{m i n})$} \\
\hline Temperature & 134 & 136 & 134 & 136 & 134 & 136 \\
$\left({ }^{\circ} \mathbf{C}\right)$ & 2.5 & 2.8 & $9.23 \mathrm{e}-05$ & $6.11 \mathrm{e}-05$ & 30.1 & 32.9 \\
\hline
\end{tabular}

crystallization beginning. Then, molecules start to reorganize themselves and they change from an intermediate degree of disorder to a more organized crystalline state. In the sequence, crystals continue to grow and after 17 minutes of isotherm it is verified the presence of regular and well defined spherulites with equivalent diameter $(18 \pm 1 \mu \mathrm{m})$ and similar morphology. Although neat PP shows crystals with homogeneous morphological characteristics, they are not very well distributed since there are regions without crystals and others where crystals are overlapped.

AFM characterization of nucleated samples was carried out at $155^{\circ} \mathrm{C}$. Figure 7 shows crystal growth and morphology over the time for PP NB 1. As expected, spherulite size is reduced compared to neat PP. The images allow visualizing the spherulite formation architecture, being

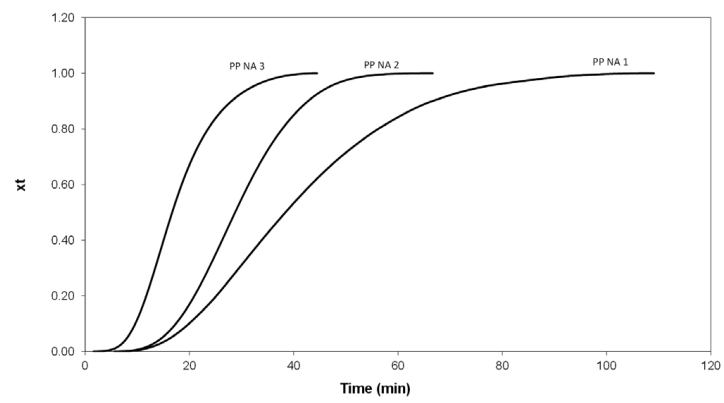

Figure 3. Isothermal crystallization curves of NA nucleated samples, at $146.5^{\circ} \mathrm{C}$.

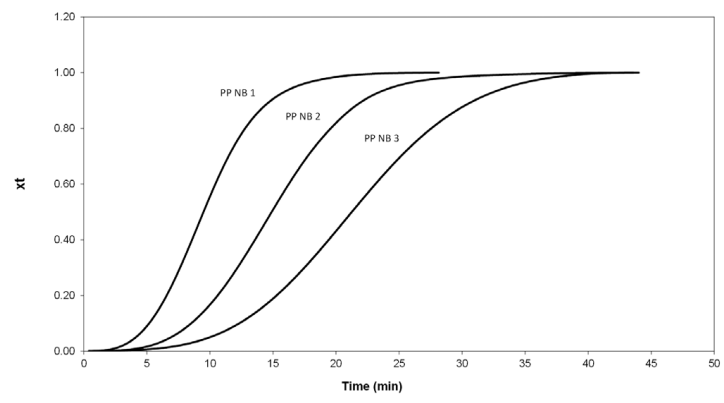

Figure 4. Isothermal crystallization curves of NB nucleated samples, at $146.5^{\circ} \mathrm{C}$.

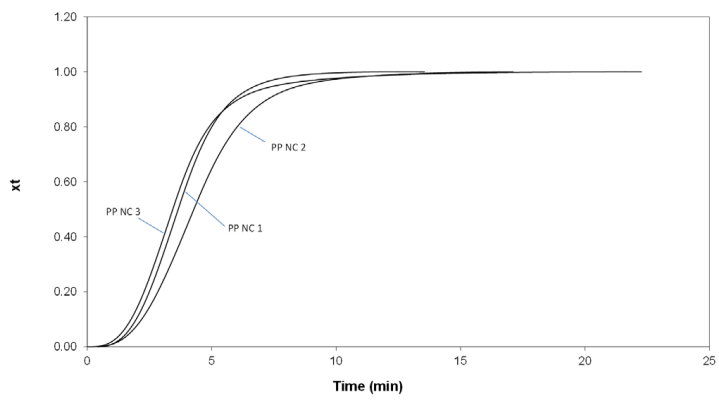

Figure 5. Isothermal crystallization curves of NC nucleated samples, at $146.5^{\circ} \mathrm{C}$. 
able to distinguish the first crystals formed at 7 minutes. At 11 minutes of isotherm, it is observed the presence of similar size lamellar sheaves randomly distributed that grow oriented away from the nucleus, followed by slower in-filling 'secondary' lamellar growth ${ }^{[17]}$. The presence of a contrast light gray indicates a melt region, whereas the dark gray represents the crystalline region.
Figure 8 shows the morphology and kinetic profile for PP $\mathrm{NC} 1$ isothermally crystallized at $155^{\circ} \mathrm{C}$. After 4 minutes of isotherm, it can be observed the presence of a large amount of embryos/nuclei satisfactory dispersed. At the height images it is clearly observed some lighter regions indicating that the crystals emerge from the molten phase, grow and form branches from the initial crystals. After 13 minutes

Table 5. Avrami parameters for nucleated PP at different isothermal temperatures.

\begin{tabular}{|c|c|c|c|c|c|c|c|c|c|}
\hline \multirow{2}{*}{$\begin{array}{l}\text { Parameters } \\
\text { Temperature }\end{array}$} & \multicolumn{3}{|c|}{$\mathbf{n}$} & \multicolumn{3}{|c|}{$\mathbf{K}$} & \multicolumn{3}{|c|}{$\frac{t_{1 / 2(\min )}}{(\mathrm{min})}$} \\
\hline & $146.5^{\circ} \mathrm{C}$ & $147^{\circ} \mathrm{C}$ & $147.5^{\circ} \mathrm{C}$ & $146.5^{\circ} \mathrm{C}$ & $147^{\circ} \mathrm{C}$ & $147.5^{\circ} \mathrm{C}$ & $146.5^{\circ} \mathrm{C}$ & $147^{\circ} \mathrm{C}$ & $147.5^{\circ} \mathrm{C}$ \\
\hline PP NA 1 & 3.1 & 3.4 & 2.7 & $2.51 \mathrm{E}-06$ & 7.94E-07 & $3.98 \mathrm{E}-05$ & 47.4 & 54.7 & 53.7 \\
\hline PP NA 2 & 3.0 & 2.7 & 3.2 & $2.51 \mathrm{E}-05$ & $1.00 \mathrm{E}-04$ & $5.01 \mathrm{E}-06$ & 28.8 & 27.3 & 40.7 \\
\hline PP NA 3 & 2.1 & 2.1 & 2.2 & $2.51 \mathrm{E}-03$ & $1.58 \mathrm{E}-03$ & $6.31 \mathrm{E}-04$ & 16.7 & 19.1 & 24.6 \\
\hline PP NB 1 & 3.1 & 3.0 & 3.4 & $6.31 \mathrm{E}-04$ & $6.31 \mathrm{E}-04$ & $1.58 \mathrm{E}-05$ & 9.5 & 10.2 & 11.8 \\
\hline PP NB 2 & 3.1 & 3.0 & 3.1 & $1.26 \mathrm{E}-04$ & $1.58 \mathrm{E}-03$ & $2.51 \mathrm{E}-05$ & 14.9 & 16.3 & 20.0 \\
\hline PP NB 3 & 3.5 & 3.2 & 3.4 & $1.58 \mathrm{E}-05$ & $3.16 \mathrm{E}-05$ & $1.58 \mathrm{E}-05$ & 21.3 & 22.0 & 24.0 \\
\hline PP NC 1 & 3.0 & 3.2 & 3.1 & $1.00 \mathrm{E}-02$ & $6.31 \mathrm{E}-03$ & $3.16 \mathrm{E}-03$ & 4.3 & 4.8 & 5.9 \\
\hline PP NC 2 & 2.9 & 2.7 & 2.9 & $1.58 \mathrm{E}-02$ & $2.00 \mathrm{E}-02$ & $1.00 \mathrm{E}-02$ & 3.7 & 3.8 & 4.4 \\
\hline PP NC 3 & 2.7 & 2.9 & 3.1 & $2.51 \mathrm{E}-02$ & $1.58 \mathrm{E}-02$ & 7.94E-03 & 3.4 & 3.8 & 4.4 \\
\hline
\end{tabular}
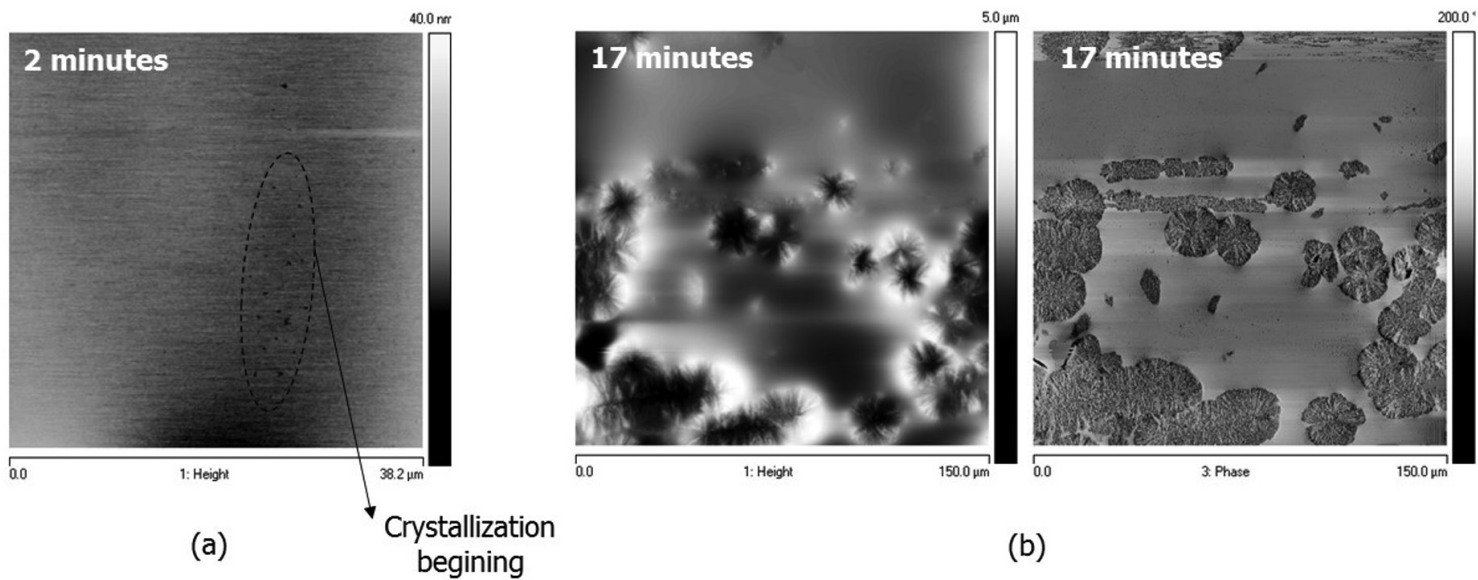

(a) begining

(b)

Figure 6. AFM images of PP isothermally crystallized at $145^{\circ} \mathrm{C}$ (a) $2 \mathrm{~min}$. and (b) $17 \mathrm{~min}$.

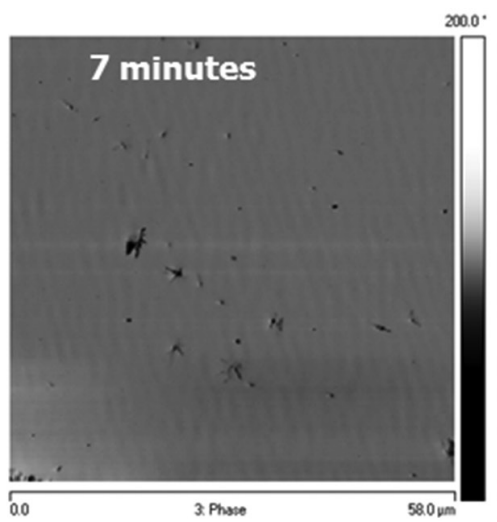

(a)

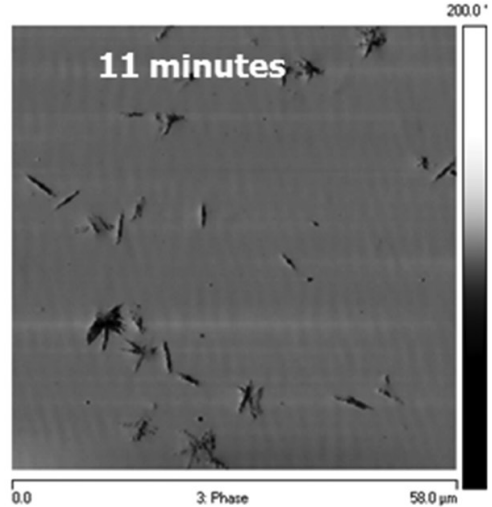

(b)

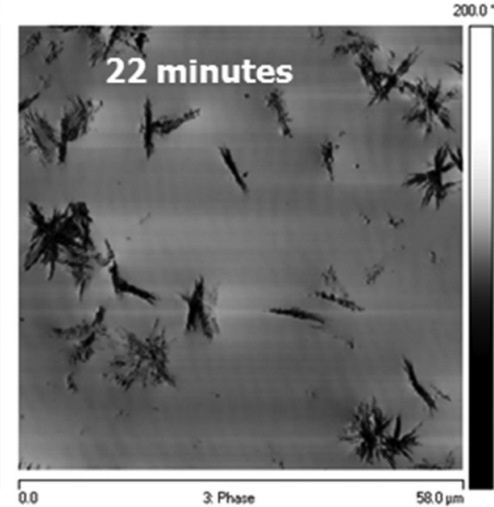

(c)

Figure 7. AFM images of PP NB 1 isothermally crystallized at $155^{\circ} \mathrm{C}$ (a) $7 \mathrm{~min}$., (b) $11 \mathrm{~min}$. and (c) $22 \mathrm{~min}$. 
of isotherm, more than $50 \%$ of the sample is crystallized. NC produces crystals with smaller size and faster kinetic profile when compared to the other nucleating agents. These observations are in agreement with DSC crystallization kinetics studies, confirming the faster crystallization rate showed by the samples nucleated with NC.

Comparing AFM images of PP NB 1 and PP NC 1 obtained at $155{ }^{\circ} \mathrm{C}$ after 22 minutes and 13 minutes of isotherm, respectively, (Figure 9a and Figure 9b) it is possible to observe that both show similar morphology. However, the presence of $\mathrm{NC}$ contributes to reduce the size of the crystals and increase the number of crystallization nuclei.

Figure 10 shows the AFM images of sample PP NA 1 , where it is not observed the characteristic spherulite morphology or other similar structures. It is verified the presence of a very thin and unique fibrillar structure intertwining networks without the formation of specific nuclei. Similar structures were also observed in some studies carried out with derivatives of sorbitol nucleating agents ${ }^{[15,17,18]}$. Probably this morphology is responsible for the improvement in the optical properties, reducing the interaction between the polymer crystalline phase and visible light. Due to this behavior, NA can also be applied as clarifier.

\subsection{Optical properties}

As expected, nucleated samples show optical properties improvements. The exceptions are the samples nucleated with NB, as can be observed in Figure 11 and 12. Samples

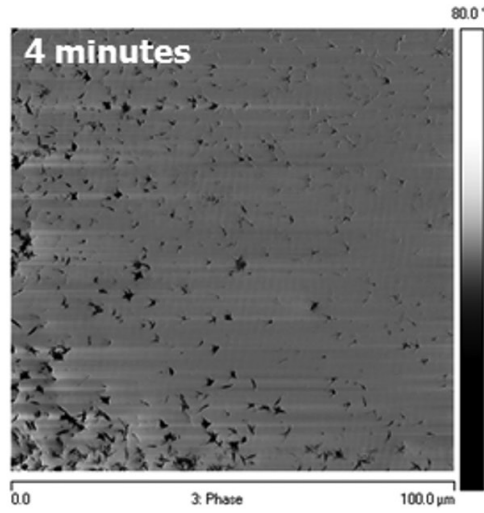

(a)

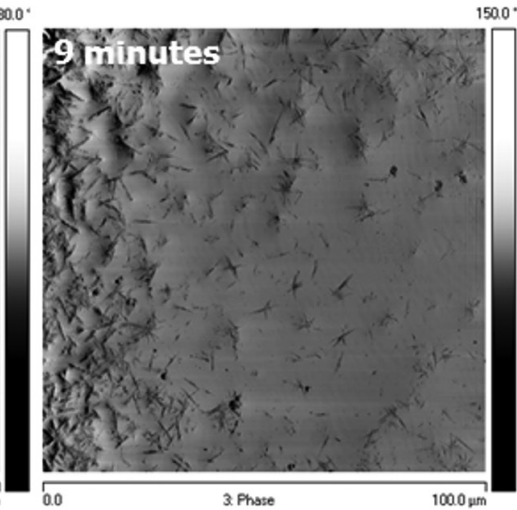

(b)

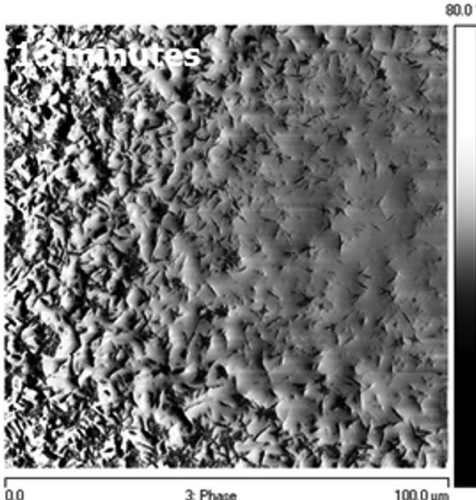

(c)

Figure 8. AFM images of PP NC 1 isothermally crystallized at $155^{\circ} \mathrm{C}$ (a) 4 min., (b) 9 min. and (c) 13 min.

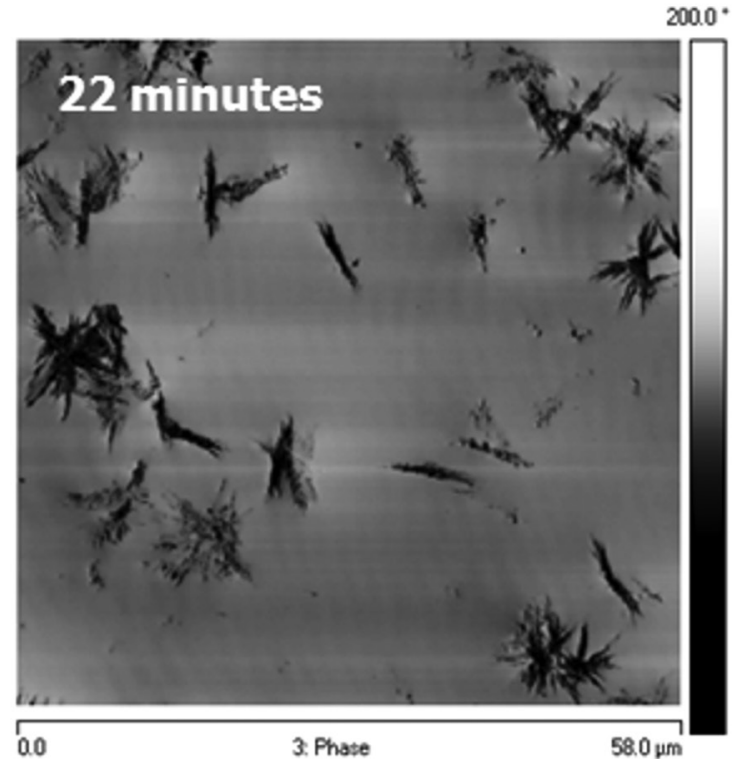

(a)

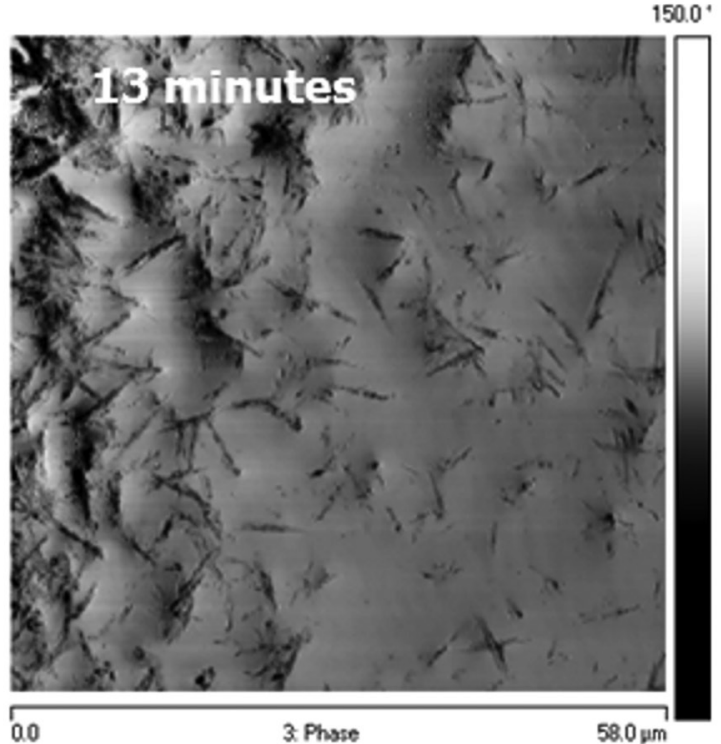

(b)

Figure 9. Comparison between spherulite size of sample (a) PP NB $1\left(22\right.$ minutes of isotherm, $\left.155^{\circ} \mathrm{C}\right)$ and (b) PP NC 1 (13 minutes of isotherm, $\left.155^{\circ} \mathrm{C}\right)$. 


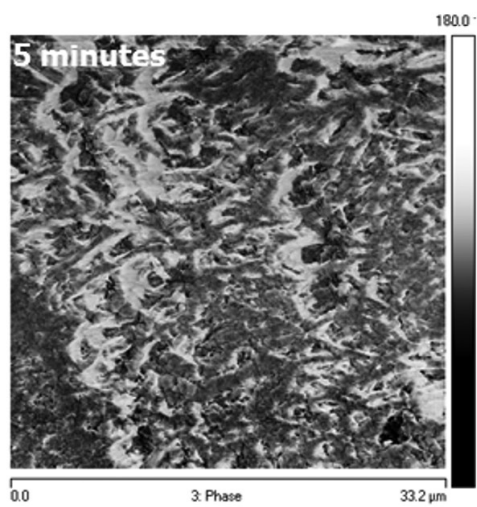

(a)

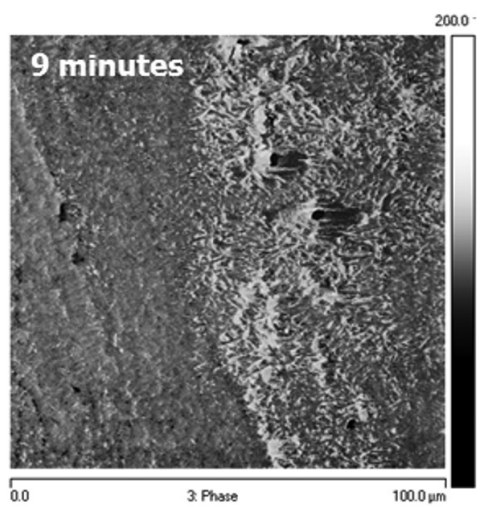

(b)

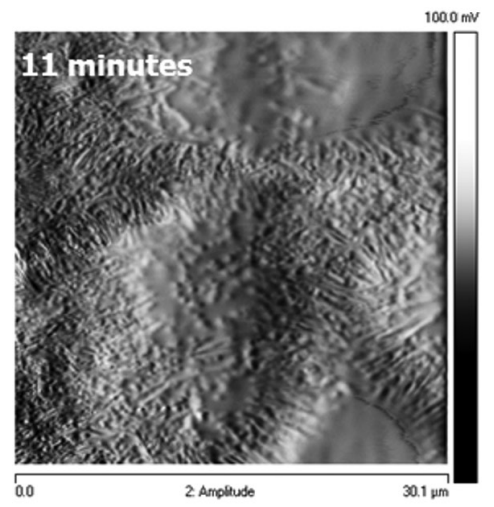

(c)

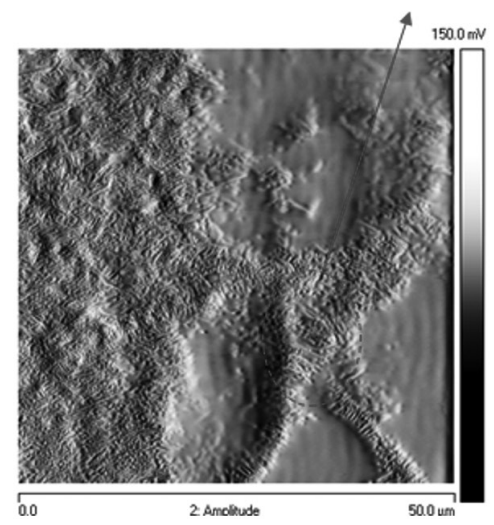

Figure 10. AFM images of PP NA 1 isothermally crystallized at $155^{\circ} \mathrm{C} \mathrm{(a)} 5$ min., (b) 9 min. and (c) 11 min.

nucleated with NA show the best improvement in optical properties, as expected for a clarifier. This better performance can be explained by its fibrillar structure, as could be seen in AFM images (Figure 10). Clarifying agents such as NA dissolve and mix with molten PP during melt processing. Upon cooling, the clarifying agent crystallizes first in the form of a three-dimensional nanometric fibrillar network and acts as a clarifying agent for PP. This fibrillar network ensures extremely fine dispersion of the nuclei and can facilitate the subsequent processes of nucleation and crystal growth ${ }^{[12]}$. The crystallites obtained are so small that incident light scattering is significantly decreased and, by consequence, optical properties are improved. As the amount of NA increases, gloss improves gradually and haze decreases. A maximum of $40 \%$ increase of gloss and a maximum of $70 \%$ reduction in haze are achieved compared to neat PP. It is observed an increase of $17 \%$ in gloss and a decrease of $36 \%$ in haze with NC addition, being the improvements almost the same for the three amounts tested. When NB is added, it is observed a decrease in optical properties, about $3 \%$ in gloss and an increase of $20 \%$ in haze. Although samples nucleated with NB show a reduction in crystal size compared to neat PP (Figures 6 and 7), there is an increase of haze. This negative effect on optical properties could be consider as a consequence of the agglomeration caused by the excess of NB, but even samples nucleated with $1000 \mathrm{ppm}$ of NB (the optimum amount tested for NA) did not show an improvement in these properties.

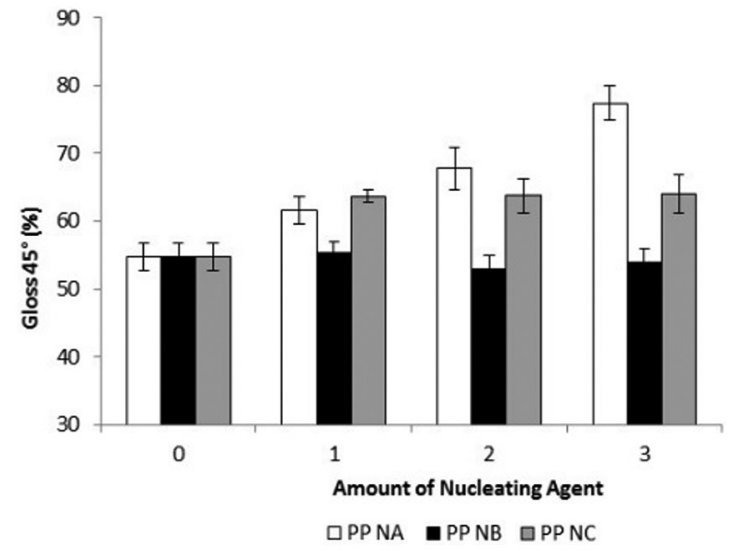

Figure 11. Gloss results of neat and nucleated PP.

PP nucleation studies ${ }^{[19,20]}$ show that calcium stearate, used as anti-acid in these formulations, may interfere in NB action, decreasing its performance as nucleating agent. Some studie ${ }^{[10,19]}$ propose an ion interchange between calcium and sodium, forming compounds that are not nucleating agents. However, Dieckmann ${ }^{[20]}$ showed that this negative effect occurs not by the calcium presence but by the presence of a metallic ion stearate. It was also demonstrated that the use of sodium stearate in samples nucleated with NB do not prejudice the efficiency of the nucleating agent. 
In order to check the influence of calcium stearate in the performance of NB, it was produced one sample with $1000 \mathrm{ppm}$ of NB without calcium stearate. Thermal and optical properties were measured and the results are shown in Table 6. Although there are no differences in crystallization temperature, it is observed an improvement in optical properties with the absence of calcium stearate. A reduction of about $15 \%$ in haze is obtained when compared to the sample containing calcium stearate, confirming the negative interaction.

As NC is also a sodium salt and do not melt into the polymer mass, like NB, it was prepared a sample with $1000 \mathrm{ppm}$ of $\mathrm{NC}$ without calcium stearate in order to verify if there is also an interference between these additives. Analyzing Table 7, it is not verified the same negative influence. The sample without calcium stearate shows a decrease in Tc and gloss and an increase in haze, when compared to the sample with calcium stearate. This result is according to data showed in the patent US2006/0142452 A1 ${ }^{[20]}$, where different stearates were tested in formulations with $\mathrm{NC}$ and it was observed an optimization of NC performance when used with calcium or zinc stearate.

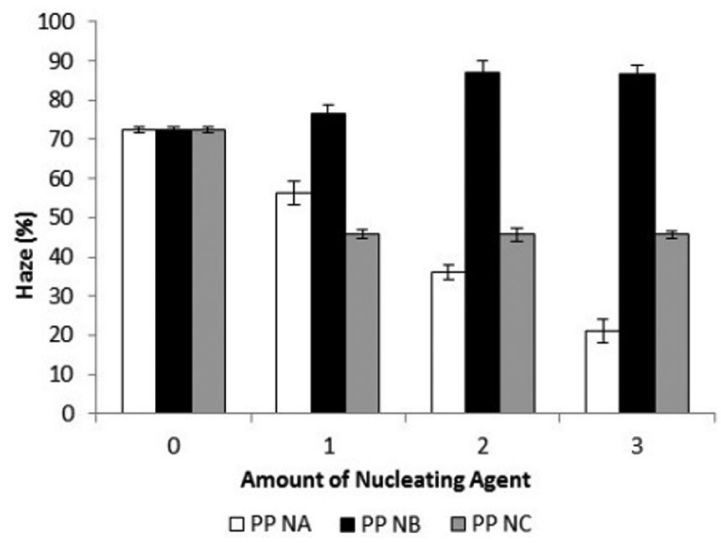

Figure 12. Haze results of neat and nucleated PP.

Table 6. Influence of calcium stearate in samples nucleated with NB.

\begin{tabular}{cccc}
\hline Properties & Neat PP & PP NB 1 & $\begin{array}{c}\text { PP NB 1 } \\
\text { (without CaSt) }\end{array}$ \\
\hline Gloss $45^{\circ}(\%)$ & $54.7 \pm 2$ & $55.4 \pm 1.6$ & $58.4 \pm 0.4$ \\
Haze $(\%)$ & $72.5 \pm 0.8$ & $76.5 \pm 2.4$ & $64.8 \pm 1.8$ \\
$\operatorname{Tc}\left({ }^{\circ} \mathrm{C}\right)$ & 113 & 132 & 132 \\
\hline
\end{tabular}

Table 7. Influence of calcium stearate in samples nucleated with NC.

\begin{tabular}{cccc}
\hline Properties & Neat PP & PP NC 1 & $\begin{array}{c}\text { PP NC 1 } \\
\text { (without CaSt) }\end{array}$ \\
\hline Gloss $45^{\circ}(\%)$ & $54.7 \pm 2$ & $63.7 \pm 0.9$ & $58.9 \pm 0.6$ \\
$\mathrm{Haze}(\%)$ & $72.5 \pm 0.8$ & $45.8 \pm 1.1$ & $65.6 \pm 0.3$ \\
$\mathrm{Tc}\left({ }^{\circ} \mathrm{C}\right)$ & 113 & 136 & 133 \\
\hline
\end{tabular}

\section{Conclusions}

PP nucleated samples showed different characteristics and behavior according to the nucleating agent type and amount used. The old generation and more commom nucleating agent tested (sodium benzoate) showed some limitations regarding agglomeration and interaction with stearates, but it is a good choice to get improvements in PP thermal properties. Hyperform ${ }^{\circledR} \mathrm{HPN}-68 \mathrm{~L}$, an advanced nucleating agent, showed to be more efficient to accelerate crystallization, even with low amounts. Also, it was possible to understand why PP nucleated with Millad ${ }^{\circledR} 3988$ shows very good improvements in optical properties through AFM images, where a network of fibrillar structure was observed instead of defined spherulites.

It was also possible to verify that there is an optimum amount of nucleating agent to reach the best performance and properties in nucleated PP and it depends on the type of nucleating agent. In many cases, the use of higher amounts of these additives is unnecessary and, even, as in the case of sodium benzoate, it can affect optical properties.

\section{Acknowledgements}

Authors would like to thank Braskem S.A. and UFRGS for supporting this work.

\section{References}

1. Mubarak, Y., Harkin-Jones, E., Martin, P. J., \& Ahmad, M. (1999). Crystallization of isotactic polypropylene: pigment, nucleating agent and recycling effects. In Proceedings of $57^{\circ}$ SPE ANTEC (pp. 3796-3800). New York: SPE.

2. Wang, K., Mai, K., \& Zeng, H. (2000). Isothermal crystallization behavior and melting characteristics of injection sample of nucleated polypropylene. Journal of Applied Polymer Science, 78(14), 2547-2553. http://dx.doi.org/10.1002/10974628(20001227)78:14<2547::AID-APP160>3.0.CO;2-F.

3. Menyhárd, A., Gahleitner, M., Varga, J., Bernreitner, K., Jääskeläinen, P., Øys, H., \& Pukánszky, B. (2009). The influence of nucleus density on optical properties in nucleated isotactic polypropylene. European Polymer Journal, 45(11), 3138-3148. http://dx.doi.org/10.1016/j.eurpolymj.2009.08.006.

4. Marco, C., Ellis, G., Gomez, M. A., \& Arribas, J. M. (2003). Analysis of the isothermal crystallization of isotactic polypropylene nucleated with sorbitol derivatives. Journal of Applied Polymer Science, 88(9), 2261-2274. http://dx.doi. org/10.1002/app.11935.

5. Binsbergen, F. L., \& Lange, B. G. M. (1970). Heterogeneous nucleation in the crystallization of polyolefins: Part 2. Kinetics of crystallization of nucleated polypropylene. Polymer, 11(6), 309-332. http://dx.doi.org/10.1016/0032-3861(70)90071-6.

6. Hay, J. N. (1971). Application of the modified avrami equations to polymer crystallisation kinetics. Polymer Journal, 3(2), 74-82. http://dx.doi.org/10.1002/pi.4980030205.

7. Supaphol, P. (2001). Application of the Avrami, Tobin, Malkin, and Urbanovici-Segal macrokinetic models to isothermal crystallization of syndiotactic polypropylene. Thermochimica Acta, 370(1-2), 37-48. http://dx.doi.org/10.1016/S00406031(00)00767-X.

8. Zhuomin, D., \& Spruiell, J. E. (1997). Interpretation of the nonisothermal crystallization kinetics of polypropylene using a power law nucleation rate function. Journal of Polymer Science. Part B, Polymer Physics, 35(7), 1077-1093. http:// 
dx.doi.org/10.1002/(SICI)1099-0488(199705)35:7<1077::AIDPOLB7>3.0.CO;2-T.

9. Li, C. C., Zhang, D., \& Li, Z. Y. (2002). The effects of alkaline earth dehydroabietate on the crystallization process of polypropylene. Journal of Applied Polymer Science, 85(13), 2644-2651. http://dx.doi.org/10.1002/app.10545.

10. Zhao, X. E., \& Dotson, D. L. (2002). US Patent No. 6465551 B1. Alexandria, Virginia: USPTO.

11. Jang, G. S., Cho, W. J., \& Ha, C. S. (2001). Crystallization behavior of polypropylene with or without sodium benzoate as a nucleating agent. Journal of Polymer Science. Part B, Polymer Physics, 39(10), 1001-1016. http://dx.doi.org/10.1002/ polb.1077.

12. Libster, D., Aserin, A., \& Garti, N. (2006). A novel dispersion method comprising a nucleating agent solubilized in a microemulsion, in polymer matrix. I. Dispersion method and polymer characterization. Journal of Colloid and Interface Science, 299(1), 172-181. http://dx.doi.org/10.1016/j.jcis.2006.01.064. PMid: 16554065 .

13. Botkin, J. H., Dunski, N., \& Maeder, D. (2002). Improving molding productivity and enhancing mechanical properties of polypropylene with nucleating agents. Kwinana: Ciba Speciality Chemicals.

14. Santamaria, E., Phan, H. D., \& Killough, L. (2008). Clarified polypropylene - old technology vs. new chemistry. In SPE Polyolefins 2008 Proceedings (pp. 1686-1692). Houston: SPE.
15. Wang, K., Zhou, C., Tang, C., Zhang, Q., Du, R., Fu, Q., \& Li, L. (2009). Rheologically determined negative influence of increasing nucleating agent content on the crystallization of isotactic polypropylene. Polymer, 50(2), 696-706. http:// dx.doi.org/10.1016/j.polymer.2008.11.019.

16. Hobbs, J. K. (2003). In-situ AFM of polymer crystallization. Chinese Journal of Polymer Science, 21(2), 129-133.

17. Tenma, M., \& Yamaguchi, M. (2007). Structure and properties of injection-molded polypropylene with sorbitol-based clarifier. Polymer Engineering and Science, 47(9), 1441-1446. http:// dx.doi.org/10.1002/pen.20839.

18. Nogales, A., Mitchell, G. R., \& Vaughan, A. S. (2003). Anisotropic crystallization in polypropylene induced by deformation of a nucleating agent network. Macromolecules, 36(13), 4898-4906. http://dx.doi.org/10.1021/ma0343028.

19. Kurja, J., \& Mehl, N. A. (2001). Plastics additives handbook. Munich: Hanser.

20. Dieckmann, D. (2001). Effect of various acid-neutralizers on the crystallization temperature of nucleated polypropylene. Journal of Vinyl and Additive Technology, 7(1), 51-55. http:// dx.doi.org/10.1002/vnl.10264.

Received: May 08, 2015

Revised: Oct. 30, 2015

Accepted: Dec. 15, 2015 